\title{
Surgical Approach of Open Reduction and Internal Fixation for Proximal Humeral Fracture in the Elderly
}

\author{
Liu Rui Jia, Meng Qing Qi, Li Si Ming* \\ Department of Orthopedics, Guangzhou Red Cross hospital, Medical College, Jinan University, Guangzhou, China \\ Email address: \\ 374144868@qq.com (Liu Rui Jia), 13929526981@126.com (Meng Qing qi),drsmli@163.com (Li Si ming) \\ ${ }^{*}$ Corresponding author
}

To cite this article:

Liu Rui Jia, Meng Qing Qi, Li Si Ming. Surgical Approach of Open Reduction and Internal Fixation for Proximal Humeral Fracture in the Elderly. Journal of Surgery. Vol. 8, No. 2, 2020, pp. 56-61. doi: 10.11648/j.js.20200802.13

Received: February 18, 2020; Accepted: March 3, 2020; Published: March 18, 2020

\begin{abstract}
Background: The incidence of proximal humeral fracture is increasing gradually. Many patients choose open reduction and internal fixation. With the maturity of surgical technology and thought, people begin to think about the optimization of surgical effect from the surgical incision, including less trauma, less bleeding, less postoperative complications and fast postoperative recovery. However, due to the complexity of shoulder anatomy, scholars have created different surgical approaches from different perspectives. Objective: Although the effect of open reduction and internal fixation is confirmed, there are still some differences in the effect of different surgical approaches. We need to study the summary and research progress of surgical approach for proximal humeral fracture, which is conducive to the selection of the optimal approach for incision, so as to improve the prognosis. Method: Selective literature review. Result: At present, common surgical approaches include lateral approach, anteromedial approach, anterolateral approach, small incision approach and other approaches. This paper describes and compares the advantages and disadvantages of each approach, so as to choose the best approach for different fracture types. Conclusion: Based on the complexity of the anatomical relationship of the shoulder joint, the displacement, classification of the fracture, the proximal humerus are opened and exposed from different perspectives. Choosing a safe surgical approach is one of the key links of the whole operation and plays an important role in the postoperative effect. In this paper, the common approaches and new approaches of open reduction and internal fixation for proximal humeral fracture are reviewed, which provides new ideas for the design of surgical scheme.
\end{abstract}

Keywords: Surgical Approach, Proximal Humeral Fracture, Open Reduction, Internal Fixation

\section{Introduction}

As the acceleration of the aging process in society, the proportion of middle-aged and elderly is increasing. The proximal humeral fractures is one of the four most common fractures in the elderly [1]. The incidence rate is increasing year by year. It accounts for $7-9 \%$ of all body fractures [2, 3], and the incidence rate of the female is higher than males. The reason is also related to the higher incidence of osteoporosis in elderly women [4]. The fracture often occurs in the low energy injury caused by falling over the horizontal ground, arm extension and standing position [5, 6]. Although the previous literature has pointed out that about $60-80 \%$ of non displaced or slightly displaced fractures can be treated conservatively [7], open reduction and plate internal fixation is usually required to restore the normal and stable anatomical structure of the proximal humerus for displaced and multi-part fractures [8]. In addition, compared with the past, expanding the scope of surgical indications would reduce the threshold of surgical indications [9]. Many complex proximal humeral fractures also choose open reduction and internal fixation. Most doctors focus on the restoration of the anatomical position of the joint, the strong internal fixation of the operation, the repair of the damaged rotator cuff tissue and the early restoration of the patients' activity function, while the discussion and summary of the surgical approach are few in academic and in practice. Although the surgical technique is mature and the treatment effect is accurate, there are still some differences in the surgical effects, postoperative rehabilitation, and postoperative complications when choosing different surgical approaches. Hence, it is necessary to understand the research progress, the summary of the surgical approach and the 
selection of the optimal approach to develop the surgical plan and improve the prognosis.

\section{Anatomy}

Due to the complex anatomical relationship among the muscles, blood vessels and nerves of the shoulder joint, it is relatively difficult to choose the surgical approach, which requires doctors to have a thorough grasp of the anatomy of the shoulder joint and the displacement of the fracture. The posterior bundle of brachial plexus continued to be an axillary nerve. The projection position of the axillary nerve trunk is $5.0 \mathrm{~cm}-7.4 \mathrm{~cm}$ away from the lateral side of the acromion [10]. It is initially located on the lateral side of the radial nerve and behind the axillary artery. The anterior, middle and posterior deltoid are innervated along with the deep layer of the deltoid. The deltoid is divided into three heads by the muscular space, which wraps around the shoulder joint from the front side, the outside side and the back side [11]. It starts from 1/3 outside the clavicle, lateral to the acromion and mesoscapula, and synthesizes a tendon to stop at the trochanter of deltoid outside the humerus. The broken end of the fracture can damage the axillary nerve, resulting in the paralysis of the deltoid and the limitation of shoulder abduction. The subclavian artery continues as the axillary artery and the brachial artery continues along the teres major tendon and the lower margin of the latissimus dorsi. The deep posterior humeral circumflex artery of deltoid bypassed the surgical neck and anastomosed with the anterior humeral circumflex artery. The anterior and posterior humeral circumflex brachial arteries provide most of the blood of the humeral head and the great tubercle of the humerus [12].

\section{Surgical Approach}

Lateral approach: Longitudinal incision is made from the lateral margin of the acromion to the lateral side of the upper humerus (Figure 1). The deltoid is bluntly separated into the axillary nerve along with the muscle fiber space. The assistant pulls the deltoid to both sides, fully exposing the broken end of the fracture. The axillary nerve around the surgical neck of the humerus should be protected when exposing the surgical area. The surgical approach is simple and quick, and the risk of axillary nerve injury is low. The operative field of vision is clear, and the lateral surface of the proximal humerus is well exposed. Compared with the anteromedial approach, the lateral approach is more convenient to detect displaced fractures. The operation of plate placement is relatively easy and convenient [13], and-functional recovery is good. The risk of axillary paralysis is low and no serious complications are found $[14,15]$. Korkmaz et al. studied and analyzed that for AO / ASIF B and C type fractures, the effect of lateral approach on reduction of the humeral head and the great tubercle of the humerus was better than that of anteromedial approach. The postoperative shoulder function score is higher. During the operation, $270^{\circ}$ reduction and fixation of proximal humerus fracture, and reduction and fixation of posterior fracture are more convenient. The clear exposure of axillary nerve can reduce iatrogenic injury [13]. However, in order to better expose the steel plate area during the operation, it is often easy to over pull the muscle and peel off too much soft tissue. The decrease of curative effect in some patients may be related to the over the destruction of soft tissue and the influence of fracture blood supply [16]. And the anteromedial fracture block is difficult to expose, which is not conducive to operation. Therefore, if we want to choose the lateral approach, we should master surgical skills. It can reduce the overstretching of muscle and the peeling of soft tissue, especially for complex comminuted fracture. More attention should be paid to the operation of visual field exposure to reduce the incidence of complications.

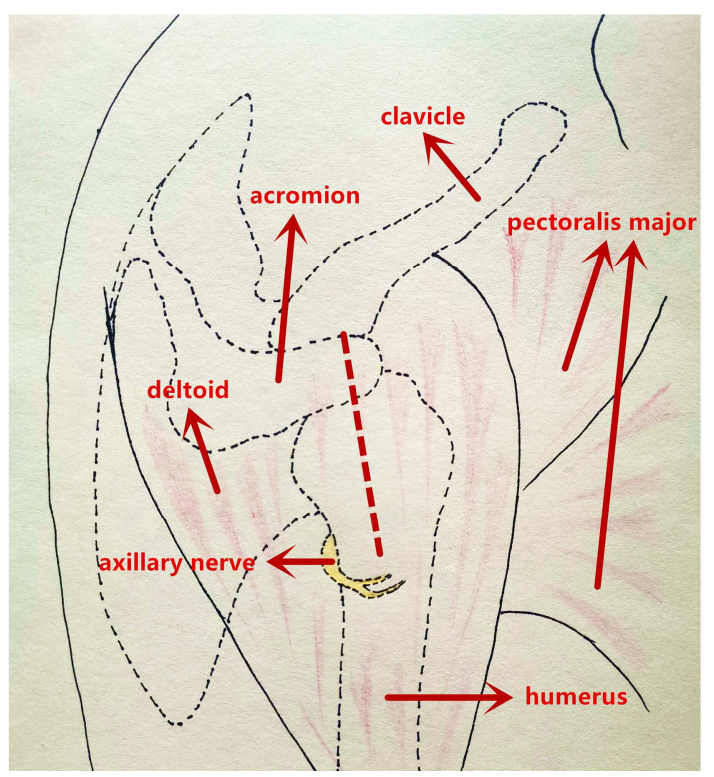

Figure 1. Lateral approach.

Anteromedial approach: a longitudinal incision is made from the front of the shoulder joint, starting from the coracoid process to the medial and ending at the deltoid. After skin incision, the cephalic vein is found, which is the anatomical mark of the space (Figure 2). Blunt separation of the space between the deltoid and pectoralis major, if necessary, cut off the beginning of the anterior deltoid tendon, and fully expose the fracture of the valgus tissue. However, it is easy to aggravate the degree of blood damage of small fracture block and musculocutaneous nerve, which may affect the abduction and anteflexion of the shoulder joint. During the separation process, the damage to the blood circulation of the joint capsule and the rotator cuff should be minimized. Meanwhile, the cephalic vein should be protected. It is the most familiar and classical surgical approach for most doctors [17-19], and it can maximize the surgical area compared with the other two classic approaches. Harmer et al. also concluded that this approach can improve the visual effect of the surgical field by comparing it with the quantitative exposure surface area of the anterolatera approach [20]. The conclusion is the same as that of other authors [16]. But there are some limitations into this approach. Because the deltoid is fan-shaped and spreads 
around the upper humerus. It is difficult to enter the posterolateral side of the shoulder joint when the fracture of the great tubercle of the humerus is restored or the implant is placed [21-23]. It is often necessary to dissect the lateral humeral tissue from the inside out, but this operation is easy to damage the anterior humera circumflexl artery. There is a risk of ischemic necrosis of the humeral head [24-27]. According to Cardet's literature, the incidence of ischemic necrosis of the humeral head was $37 \%$ [28]. This may be related to the injury of blood vessels. Therefore, doctors should pay attention to the protection of the artery and its branches during the operation, which plays an important role in the prevention of ischemic necrosis of the humeral head [29]. But Hettrich's study found that the posterior humeral circumflex artery was the main blood supply artery of the humeral head. The anterior humeral circumflex artery mainly supplies the great tubercle of the humerus [30]. This also explains that when the proximal humeral fracture destroys the anterior humeral circumflex artery, the humeral head is not necessarily ischemic necrosis. So we should pay attention to the posterior humeral circumflex artery. There should not be too much peeling of the posterior medial tissue. During reduction, we should also pay attention not to damage the artery and reduce the risk of ischemic necrosis of the humeral head.

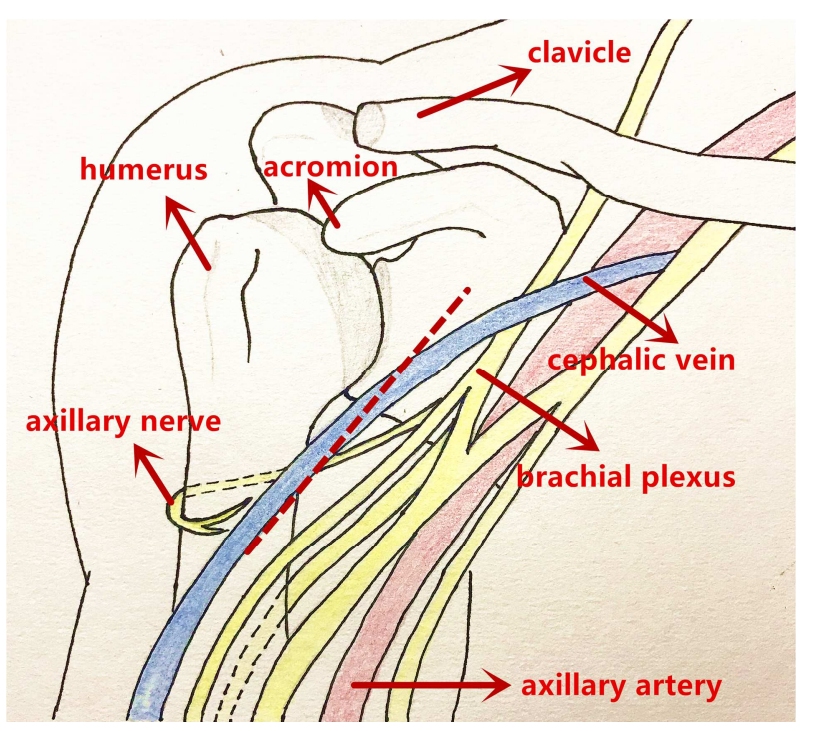

Figure 2. Anteromedial approach..

Anterolateral approach: According to Gardner's description, the approach is to open and expose the lateral humerus and the great tubercle of the humerus between the anterior and the middle deltoid bundles. It is beneficial to the indirect reduction of the humeral head, reducing the peeling of soft tissue and the damage of blood circulation, and reducing the damage of deltoid [23, 30-33]. And between the muscle bundles belong to the area without blood vessels, also better placed with a fixed angle of the endophyte [16]. But we need to pay attention to the anatomic location of the axillary nerve (Figure 3). The main risk of this approach is to injure the axillary nerve, so it is necessary to dissect the axillary nerve to reduce the risk of iatrogenic nerve injury $[10,34,35]$. No iatrogenic injury is caused to the axillary nerve when it is not more than $6 \mathrm{~cm}$ in the longitudinal incision and $1 \mathrm{~cm}$ in the traction of the axillary nerve from the bone cortex [31]. This approach has the advantages of less trauma, shorter time and less bleeding compared with other approaches. However, it is more difficult to select this approach than other approaches in the subsequent second operation. Due to the incidence rate of proximal humeral fractures is high in the elderly. If there is no special discomfort, there is no need for second operations to remove the plate to avoid the risk of reoperation [36]. Isiklar et al. compared with the anteromedial approach, found that patients in the anterolateral approach group showed better stable scores in the early postoperative period. And it can better restore the humeral head and the great tubercle of the humerus [37]. In terms of complications, compared with the anteromedia approach, Benjamin assessed the incidence of complications to be about the same, but the distribution of complications was different. The complications of the anterolateral approach mainly affect the head area of the humerus. This may also be due to the relatively small incision of the anterolateral approach and the insufficient field of vision to expose the head, which affects the reduction and fixation of the head fracture block. However, it is easier to fix the plate on the shaft of the humerus [38]. The bone density in the posterior, inferior and medial areas of the humeral head is higher [39]. Therefore, the placement of plates and screws to the best position during operation can promote fracture healing and reduce the risk of internal fixation loosening. Do not place the steel plate too high or too partial medial is to avoid subacromial impingement syndromet and affect the function of the internal rotation of the shoulder joint.

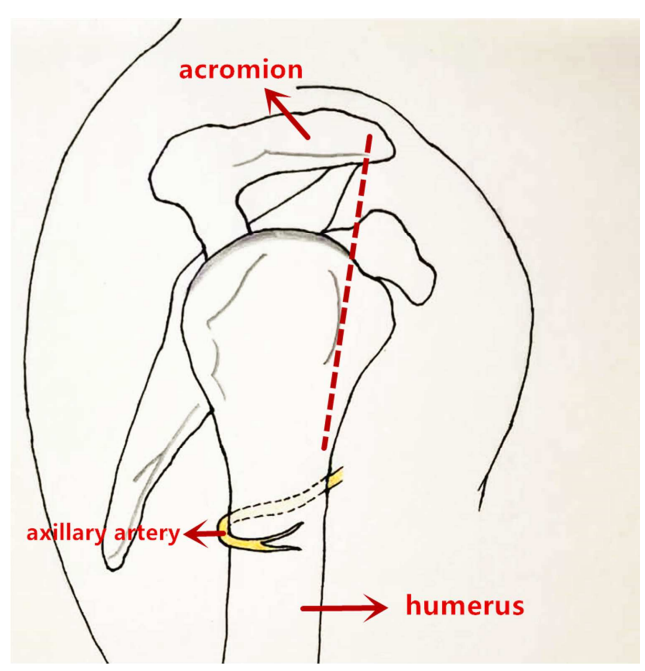

Figure 3. Anterolateral approach..

Small incision approach: The traditional approach for proximal humerus fracture has a series of disadvantages, such as single incision, long incision, large trauma, more bleeding, long postoperative rehabilitation time, which affect the surgical effect and postoperative rehabilitation. Some doctors have improved on the traditional incision. In order to reduce the length of the original traditional approach incision and achieve minimally invasive combined with MIPPO 
technology to complete the open reduction and internal fixation of fracture, $\mathrm{Li}$ et al. compared with the traditional anteromedial approach, the small incision group was superior to the traditional approach group in terms of intraoperative blood loss, operation time and postoperative function score [40]. In the same way, it can reduce the soft tissue peeling and damage through the small incision of the anterolateral approach combined with MIPPO technology. The combination of the anterolateral approach with MIPPO technology to reduce soft tissue dissection and injury, accelerate postoperative wound recovery and relieve pain, improve fracture end healing [41]. Because of the risk of injury to the axillary nerve, the distal screw should not be used on the internal plant [42]. However, no damage to the nerve is found in the small incision approach [43]. In the view of the potential risk of damaging the axillary nerve [44], Buecking et al. explored the axillary nerve with their fingers in the subdeltoid capsule and marked its course on the surface [38]. Ruchholtz et al. used five hole steel plate during the operation, and the top of the steel plate contacted with the bone. Three holes at the distal end of the plate were fixed with screws to avoid the axillary nerve [45]. Additionally, the small incision approach also has some limitations. Some studies have shown that the incidence of complications is related to the professional experience of doctors [45]. For small hospitals and young doctors, the learning curve is tortuous. Because of the small incision, the exposure field of the fracture is not enough, so it is necessary to fully evaluate the fracture before an operation. During the operation, repeated fluoroscopy is needed to understand the reduction and fixation. Both patients and doctors need to bear X-ray radiation repeatedly. However, the poor reduction effect or complex proximal humeral fracture can easily lead to malunion of fracture and ischemic necrosis of fracture block [46]. But we can also foresee that with the gradual improvement of the minimally invasive approach and the improvement of surgical techniques, the small incision approach combined with MIPPO can also be used to achieve the good surgical effects for complex fractures.

Other incision approaches:

Extended anterolateral approach: Mackenzize reported an extended anterolateral approach for shoulder replacement. The operator can safely expose the anterolateral proximal humerus. No axillary nerve injury is found in all patients. However, we find that the evaluation method of the axillary nerve is abnormal, and the evaluation methods used for different patients are not the same [47]. Gardner also exposed the axillary nerve through this approach, and no structural damage was found. Its validity and security are verified. Robinson et al. also found that this approach can avoid the iatrogenic injury of the axillary nerve caused by muscle pulling and blind reduction [22]. Mouraria combined the related literature analysis and indicated that the extended anterolateral approach can reduce the risk of iatrogenic axillary nerve injury, and the postoperative functional recovery is good [48].

Deltoid lift approach: For some complex fractures, the surgical field is often not exposed enough. Ting et al. proposed a new incision approach for transverse incision from the medial $3 \mathrm{~cm}$ of the acromioclavicular joint of the cadaveric body. The skin is cut along the shoulder joint and the forearm lateral to below the deltoid stop. The tension of the axillary nerve decreased and retracted outward. According to quantitative measurement, the surface area of the exposed surgical field is relatively large, with an average of $38 \mathrm{~cm}^{2}-53 \mathrm{~cm}^{2}$. It can not only keep the main nerve and blood vessels of the deltoid, but also displaying the key anatomical signs needed by operation [49].

Double incision approach: Gallo et al. proposed a double incision approach for complex proximal humeral fractures with tuberculum majus displacement. The anteromedial incision is used to expose the humeral head and shaft, and the lateral small incision is used to restore the tuberculum majus. The selection of the approach can make the steel plate pass through the injured side to fix the fracture block. It can not only reduce the peeling of soft tissue and the damage of blood supply, but also reducing the injury of the deltoid and the iatrogenic injury of the nerve caused by excessive traction, so as to better restore the great tubercle of the humerus [50]. The potential complication of this approach is postoperative joint stiffness, so strengthening the rehabilitation exercise of patients can be significantly improved within one year.

\section{Conclusion}

Pain, deformity and limited movement of shoulder joint have a great influence on the quality of life. Proximal humeral fracture is one of the common fractures of osteoporosis in the elderly. With the progress of orthopaedic surgery and the improvement of quality of life, more and more patients often choose open reduction and internal fixation. However, the operative approach is limited by the anatomical relationship and the displacement of the fracture, and specializing in the anatomy of the shoulder joint is the beginning of the exposure of the fracture site. Based on the anatomical relationship, a variety of surgical approaches are designed for clinicians to select in specific circumstances. From the research progress of the above approaches, we find that the approach has its own advantages and disadvantages. Based on the review and summary of the original technology, incision from all angles, traditional long incision to small incision combined with minimally invasive technology, single incision to double incision, are continuous reflected and innovated in order to provide new ideas and methods for clinical application, to select an optimal surgical approach for patients, to achieve the best surgical effect.

\section{References}

[1] Burkhart KJ. The treatment of proximal humeral fracture in adults. [J]. Deutsches Ärzteblatt International, Vol. 110, No. 35-36, 2013, pp. 591-597. 
[2] Carroll EA, Schweppe M, Langfitt M, et al. Management of humeral shaft fractures [J]. The Journal of the American Academy of Orthopaedic Surgeons. Vol. 20, No 7, 2012, pp. 423-433.

[3] Aaron D, Shatsky J, Paredes JC, et al. Proximal humeral fractures: internal fixation. [J]. Journal of Bone \& Joint Surgery American Volume, Vol. 94, No. 24, 2012, pp. 2280-8.

[4] Hessmann MH, Hansen WSM, Krummenauer F, et al. Locked Plate Fixation and Intramedullary Nailing for Proximal Humerus Fractures: A Biomechanical Evaluation [J]. The Journal of Trauma: Injury, Infection, and Critical Care, Vol. 58, No. 6, 2005, pp. 1194-1201.

[5] Palvanen M, Kannus P, Niemi S, et al. Update in the epidemiology of proximal humeral fractures [J]. Clinical Orthopaedics \& Related Research, Vol. 442, 2006, pp. 87-92.

[6] Lind T, Krøner K, Jensen J. The epidemiology of fractures of the proximal humerus [J]. Archives of Orthopaedic \& Trauma Surgery. Vol. 105, No. 5, 1989, pp. 285-287.

[7] Gaebler C. Minimally displaced proximal humeral fractures. Epidemiology and outcome in 507 cases [J]. Acta Orthop Scand. Vol. 74, No. 5, 2003, pp. 580-5.

[8] Agudelo J, Schürmann, Matthias, Stahel P, et al. Analysis of Efficacy and Failure in Proximal Humerus Fractures Treated With Locking Plates [J]. Journal of Orthopaedic Trauma, Vol. 21, No. 10, 2007, pp. 676-681.

[9] Bell JE, Leung BC, Spratt KF, et al. Trends and Variation in Incidence, Surgical Treatment, and Repeat Surgery of Proximal Humeral Fractures in the Elderly [J]. Journal of Bone \& Joint Surgery American Volume, Vol. 93, No. 2, 2011, pp. 121-31.

[10] Burkhead WZ, Scheinberg RR, Box G. Surgical anatomy of the axillary nerve $[\mathrm{J}]$. Journal of Shoulder and Elbow Surgery, Vol. 1, No. 1, 1992, pp. 31-36.

[11] Marion B, Leclère, Franck M, et al. Potential axillary nerve stretching during RSA implantation: an anatomical study [J] Anatomical Science International, Vol. 89, No. 4, 2014, pp. 232-237.

[12] Menck J, Döbler A, Döhler JR.[Vascularization of the humerus] [J]. Langenbecks Archiv Für Chirurgie. Vol. 382, No. 3, 1997, pp. 123-127.

[13] Korkmaz MF, Erdem MN, Karakaplan M, et al. [Comparison of lateral deltoid splitting and deltopectoral approaches in the treatment of proximal humerus fractures] [J]. Ulusal travma ve acil cerrahi dergisi $=$ Turkish journal of trauma $\&$ emergency surgery: TJTES. Vol. 21, No. 2, 2015, pp. 113-118.

[14] Gardner MJ, Griffith MH, Dines JS, et al. The extended anterolateral acromial approach allows minimally invasive access to the proximal humerus [J]. Clinical orthopaedics and related research. No. 434, 2005, pp. 123-129.

[15] Khan LAK, Robinson CM, Will E, et al. Assessment of axillary nerve function and functional outcome after fixation of complex proximal humeral fractures using the extended deltoid-splitting approach [J]. Injury-international Journal of the Care of the Injured, Vol. 40, No. 2, 2009, pp. 181-185.

[16] Gardner MJ, Griffith MH, Dines JS, et al. A minimally invasive approach for plate fixation of the proximal humerus [J]. Bulletin. Vol. 62, No. 1-2, 2004, pp. 18-23.
[17] Cameron BD, Williams GR. Operative Fixation of Three-Part Proximal Humerus Fractures [J]. Techniques in Shoulder \& Elbow Surgery. Vol. 3, No. 2, 2002, pp. 111-123.

[18] Theodore FS, Richard JH. Displaced Proximal Humeral Fractures: Evaluation and Treatment [J]. Journal of the American Academy of Orthopaedic Surgeons. Vol. 2, No. 1, 1994, pp. 54-78.

[19] Chou YC, Tseng IC, Chiang CW, et al. Shoulder hemiarthroplasty for proximal humeral fractures: comparisons between the deltopectoral and anterolateral deltoid-splitting approaches [J]. Journal of Shoulder and Elbow Surgery, Vol. 22, No. 8, 2013, pp. e1-e7.

[20] Harmer LS, Crickard CV, Phelps KD, et al. Surgical Approaches to the Proximal Humerus: A Quantitative Comparison of the Deltopectoral Approach and the Anterolateral Acromial Approach. Journal of the American Academy of Orthopaedic Surgeons. Global research \& reviews. Vol. 2, No. 6, 2018, pp. e017.

[21] Abbott LC, Saunders JBD. Surgical approaches to the shoulder joint. [J]. Journal of Bone \& Joint Surgery American Volume, Vol. 31A, No. 2, 1949, pp. 235.

[22] Robinson CM, Khan L, Akhtar A, et al. The Extended Deltoid-Splitting Approach to the Proximal Humerus [J]. Journal of Orthopaedic Trauma, Vol. 21, No. 9, 2007, pp. 657-662.

[23] Flatow EL, Cuomo F, Maday MG, et al. Open reduction and internal fixation of two-part displaced fractures of the greater tuberosity of the proximal part of the humerus. [J]. Journal of Bone \& Joint Surgery-american Volume, Vol. 73, No. 8, 1991, pp. 1213-1218.

[24] Argyropoulos M, Kent M. Early Results of the A. L. P. S. Proximal Humerus Locking Plate [J]. The Open Orthopaedics Journal, Vol. 12, No. 1, 2018, pp. 53-58.

[25] Konrad G, Laurent Audigé, Lambert S, et al. Similar Outcomes for Nail versus Plate Fixation of Three-part Proximal Humeral Fractures [J]. Clinical Orthopaedics \& Related Research, Vol. 470, No. 2, 2012, pp. 602-609.

[26] Saran N, Bergeron SG, Benoit B, et al. Risk of axillary nerve injury during percutaneous proximal humerus locking plate insertion using an external aiming guide [J]. Injury, Vol. 41, No 10, 2010, pp. 1037-1040.

[27] Wijgman AJ, Roolker W, Patt TW, et al. Open reduction and internal fixation of three and four-part fractures of the proximal part of the humerus [J]. J Bone Joint Surg Am. Vol. 84, No. 11, 2002, pp. 1919-25.

[28] Cadet ER, Ahmad CS. Hemiarthroplasty for Three- and Four-part Proximal Humerus Fractures [J]. Journal of the American Academy of Orthopaedic Surgeons, Vol. 20, No. 1, 2010, pp. 17-27.

[29] Gerber C, Schneeberger AG, Vinh TS. The arterial vascularization of the humeral head. An anatomical study. [J]. Journal of Bone \& Joint Surgery-american Volume, Vol. 72, No. 10, 1990, pp. 1486-1494.

[30] Hettrich, Carolyn M. Quantitative Assessment of the Vascularity of the Proximal Part of the Humerus [J]. The Journal of Bone and Joint Surgery (American), Vol. 92, No. 4, 2010, pp. 943. 
[31] Gardner MJ, Boraiah S, Helfet DL, et al. The anterolateral acromial approach for fractures of the proximal humerus [J]. Journal of orthopaedic trauma. Vol. 22, No. 2, 2008, pp. 132-137.

[32] Robinson CM, Murray IR. The extended deltoid-splitting approach to the proximal humerus: VARIATIONS AND EXTENSIONS [J]. The Bone \& Joint Journal, Vol. 93-B, No. 3, 2011, pp. 387-392.

[33] Gardner MJ, Voos JE, Wanich T, et al. Vascular implications of minimally invasive plating of proximal humerus fractures $[\mathrm{J}]$. Journal of orthopaedic trauma. Vol. 20, No. 9, 2006, pp. 602-607.

[34] Rancan M, Dietrich M, Lamdark T, et al. Minimal invasive long PHILOS?-plate osteosynthesis in metadiaphyseal fractures of the proximal humerus [J]. Injury-international Journal of the Care of the Injured, Vol. 41, No. 12, 2010, pp. 1277-1283.

[35] Stecco C, Gagliano G, Lancerotto L, et al. Surgical anatomy of the axillary nerve and its implication in the transdeltoid approaches to the shoulder [J]. J Shoulder Elbow Surg, Vol. 19, No. 8, 2010, pp. 0-1174.

[36] Boesmueller S, Wech M, Gregori M, et al. Risk Factors for Humeral Head Necrosis and Non-Union After Plating in Proximal Humeral Fractures [J]. Injury, Vol. 47, No. 2, 2015, pp. 350-355.

[37] Isiklar Z, Kormaz F, Gogus A, et al. COMPARISION OF DELTOPECTORAL VERSUS LATERAL DELTOID SPLIT APPROACH IN OPERATIVE TREATMENT OF PROXIMAL HUMERAL FRACTURES. 2010.

[38] Buecking B, Mohr J, Bockmann B, et al. Deltoid-split or Deltopectoral Approaches for the Treatment of Displaced Proximal Humeral Fractures? [J]. Clinical Orthopaedics and Related Research, Vol. 472, No. 5, 2014, pp. 1576-1585.

[39] Tingart MJ, Lehtinen J, Zurakowski D, et al. Proximal humeral fractures: Regional differences in bone mineral density of the humeral head affect the fixation strength of cancellous screws [J]. Journal of Shoulder \& Elbow Surgery, Vol. 15, No. 5, 2006, pp. 0-624.

[40] Zhao L, Yang P, Zhu L, et al. Minimal invasive percutaneous plate osteosynthesis (MIPPO) through deltoid-pectoralis approach for the treatment of elderly proximal humeral fractures [J]. Bmc Musculoskelet Disord. Vol. 18, No. 1, 2017, pp. 187.
[41] Acklin YP, Sommer C. Plattenosteosynthese von proximalen Humerusfrakturen über den minimalinvasiven anterolateralen Deltasplit-Zugang $[\mathrm{J}]$. Operative Orthopädie Und Traumatologie, Vol. 24, No. 1, 2012, pp. 61-73.

[42] Apaydin N, Tubbs RS, Loukas M, et al. Review of the surgical anatomy of the axillary nerve and the anatomic basis of its iatrogenic and traumatic injury [J]. Surgical \& Radiologic Anatomy, Vol. 32, No. 3, 2010, pp. 193-201.

[43] Sohn HS, Jeon YS, Lee JH, et al. Clinical comparison between open plating and minimally invasive plate osteosynthesis for displaced proximal humeral fractures: A prospective randomized controlled trial [J]. Injury, Vol. 48, No. 6, 2017, pp. 1175-1182.

[44] Handoll HH, Madhok R. Interventions for treating proximal humeral fractures in adults $[\mathrm{J}]$. Cochrane Database of Systematic Reviews, No. 4, 2003.

[45] Ruchholtz S, Hauk C, Lewan U, et al. Minimally Invasive Polyaxial Locking Plate Fixation of Proximal Humeral Fractures: A Prospective Study [J]. Journal of Trauma. Vol. 71, No. 6, 2011, pp. 1737-1744.

[46] Luigi AR, Matteo DR, Alberto GF. Minimally Invasive Plate Osteosynthesis for Proximal Humerus Fractures: A Retrospective Study Describing Principles and Advantages of the Technique [J]. Advances in Orthopedics, Vol. 2018, 2018, pp. 1-10.

[47] D. B, Mackenzie. The antero-superior exposure for total shoulder replacement $[\mathrm{J}]$. Journal of Shoulder and Elbow Surgery, 1996.

[48] Mouraria GG, Zoppi A, Kikuta FK, et al. ANTEROLATERAL APPROACHES FOR PROXIMAL HUMERAL OSTEOSYNTHESIS: A SYSTEMATIC REVIEW [J]. Acta ortopedica brasileira. Vol. 27, No. 3, 2019, pp. 178-182.

[49] Ting M, Kusnezov N, Dunn JC, et al. The Deltoid Lift: A Cadaveric Analysis and the Literature Review of a Novel Surgical Approach to the Proximal Humerus [J]. Techniques in hand \& upper extremity surgery, Vol. 19, No. 3, 2015, pp. $120-123$.

[50] Gallo RA, Zeiders GJ, Altman GT. Two-incision technique for treatment of complex proximal humerus fractures $[\mathrm{J}]$. Journal of orthopaedic trauma. Vol. 19, No. 10, 2005, pp. 734-740. 